\title{
Safety and Efficacy of Guidezilla Extension Catheter for the Percutaneous Treatment of Complex Coronary Lesions
}

\author{
Tao Chen, ${ }^{+*}$ Weihao Xu, ${ }^{2 *}$ Yulun Cai, ${ }^{2}$ Qi Wang, ${ }^{1}$ Jun Guo, ${ }^{1}$ Yundai Chen ${ }^{1}$ \\ ${ }^{1}$ Department of Cardiology, The First Medical Centre, Chinese PLA General Hospital, Beijing, China; ${ }^{2}$ Department of Cardiology, The \\ Second Medical Centre, Chinese PLA General Hospital, National Clinical Research Center for Geriatric Diseases, Beijing, China
}

\section{ABSTRACT}

Background: The Guidezilla ${ }^{\mathrm{TM}}$ support extension catheter is designed to provide extra back-up support and efficient device delivery during complex percutaneous coronary interventions (PCIs), such as in treatment of severe calcification, tortuous chronic total occlusions (CTOs), and coronary anomalies. The aim of this study was to describe our initial experience with the Guidezilla ${ }^{\mathrm{TM}}$ extension catheter in the treatment of complex coronary artery lesions.

Methods: This study retrospectively analyzed data from 165 PCI cases that used the Guidezilla ${ }^{\mathrm{TM}}$ guide extension catheter between March 2015 and August 2017. We collected patient clinical characteristics, target lesion characteristics, and procedural details.

Results: Eighty-six percent of patients had complex Type $\mathrm{C}$ lesions, and $13.9 \%$ had Type B lesions. Lesion length ranged from $8 \mathrm{~mm}$ to $130 \mathrm{~mm}$ ( $\leq 20 \mathrm{~mm}, 15.4 \% ; 20-40 \mathrm{~mm}$, $35.8 \%$; $>40 \mathrm{~mm}, 49.1 \%)$. The right coronary artery $(59.2 \%)$ was the most common intervention vessel followed by the left ascending artery (30.6\%) and the left circumflex artery $(10.2 \%)$. CTO accounted for $38 \%$ of all lesions, followed by distortions (28\%), heavy calcification (24\%), proximal stent thrombosis $(9 \%)$, and coronary artery origin anomalies (1\%). A total of 142 patients underwent successful PCI using the Guidezilla ${ }^{\mathrm{TM}}$ extension catheter. The success rate was $86 \%$.

Conclusion: The Guidezilla ${ }^{\mathrm{TM}}$ guide extension catheter was an effective and safe technique in the transradial treatment of complex coronary lesions. Use of the Guidezilla ${ }^{\mathrm{TM}}$ guide extension catheter can shorten the procedure time and ensure overall procedural success with a reduced complication rate in cases where adequate progress using angioplasty devices has not been achieved.

\section{INTRODUCTION}

The development and application of coronary interventional devices is an important factor in improving the success rate of percutaneous coronary intervention (PCI). In the treatment of complex coronary anatomies involving severe calcification, tortuous chronic total occlusions (CTOs) and coronary anomalies, poor back-up support may result in failure of the balloon or stent to reach the targeted lesion area, and may even cause stent deformity or detachment. Therefore, various tools, such as buddy wires, anchoring balloons, and mother-child catheters [Di 2008; Saeed 2008] have been developed to increase back-up support in different complex scenarios. However, some complications still are lacking back-up support, such as anchored vascular injuries, coronary perforations, and coronary dissections [Chang 2013; Papayannis 2012].

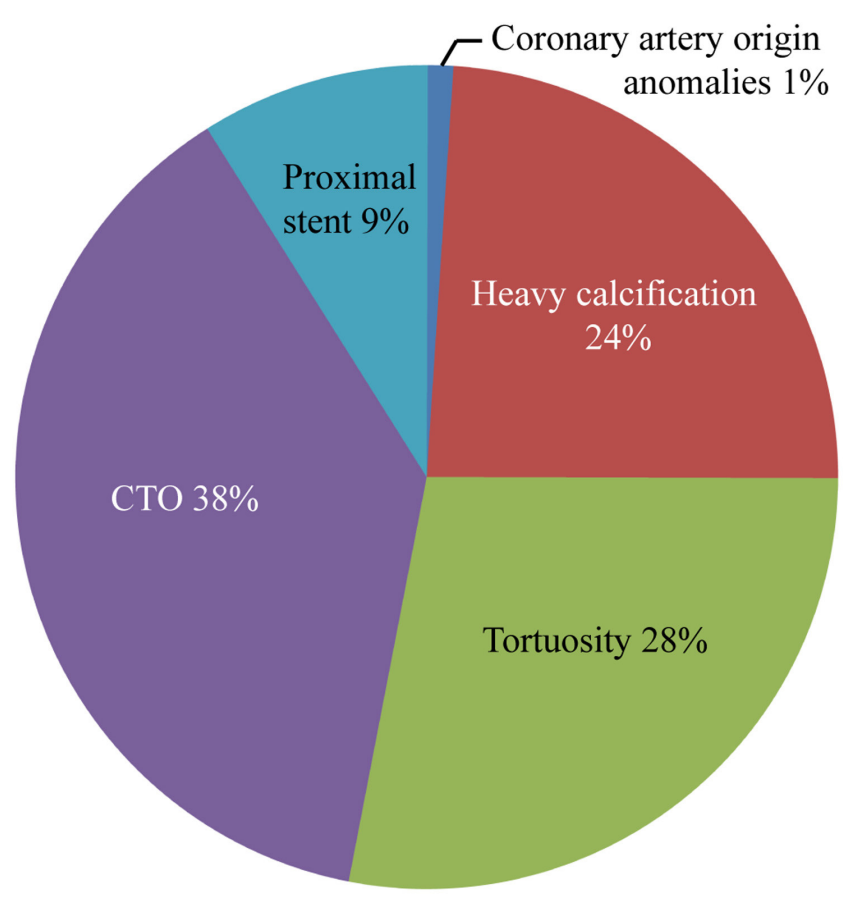

Indications for GuidezillaTM use in complex coronary interventions. 
Table 1. Patients' clinical characteristics

\begin{tabular}{lcc}
\hline Clinical characteristics & Numbers & Percentage \\
\hline Mean age (years) & $63.5 \pm 10.3$ & \\
Body mass index & $26.2 \pm 3.9$ & \\
Sex & & \\
Male & 132 & $80.0 \%$ \\
Female & 33 & $20.0 \%$ \\
Diabetes & 68 & $41.2 \%$ \\
Hypertension & 121 & $73.3 \%$ \\
Hypercholesterolemia & 58 & $35.2 \%$ \\
Chronic kidney disease & 9 & $5.4 \%$ \\
Smoking & 53 & $32.1 \%$ \\
Previous coronary intervention & 53 & $32.1 \%$ \\
Previous myocardial infarction & 37 & $22.4 \%$ \\
Previous coronary artery bypass grafting & 10 & $6.1 \%$
\end{tabular}

The Guidezilla ${ }^{\mathrm{TM}}$ extension catheter is a rapid exchange extension catheter that provides convenient and efficient back-up support in the implementation of 6-Fr guide catheters, while preserving the initially inserted wire to avoid the risk of entering the vascular compartment in cases where the wire is re-inserted [Yew 2016].

The purpose of this study was to investigate the effectiveness and safety of the Guidezilla ${ }^{\mathrm{TM}}$ extension catheter in PCIs of complex coronary lesions.

\section{MATERIALS AND METHODS}

Study design: This study retrospectively analyzed data from 165 PCI cases that used the Guidezilla ${ }^{\mathrm{TM}}$ guide extension catheter (Boston Scientific, Marlborough, MA) between March 2015 and August 2017 in our hospital's cardiac catheterization laboratory. Patients' clinical characteristics data (age, gender, smoking status, hypertension, diabetes, hyperlipidemia, myocardial infarction, and coronary artery bypass graft history) were collected. Target lesion characteristics and indication for the use of the Guidezilla ${ }^{\mathrm{TM}}$ catheter (tortuosity, heavy calcification, coronary artery origin anomalies, and CTO) and procedural details were collected and analyzed. This catheter was applied when we had difficulty in advancing a retro-guidewire through an occlusion segment into the antegrade guide catheter.

Statistical analysis: Analyses were performed using SPSS version 21.0 statistical software. Continuous variables are expressed as mean \pm standard deviation and were compared using a Student's t-test for independent samples. Nonnormally distributed continuous variables are expressed as median and interquartile range (IQR). Categorical data were compared using a chi-square test or Fisher's exact test. Relative risks (RR) are reported with $95 \%$ confidence intervals (CIs). $P$-values of $<.05$ were considered statistically significant.
Table 2. Target lesion characteristics

\begin{tabular}{ccc}
\hline & Target lesion characteristics & Number/Percentage \\
\hline Lesion type & A & $0 \%$ \\
B & $23 / 13.9 \%$ & \\
C & $142 / 86.1 \%$ & \\
Lesion length & $\leq 20 \mathrm{~mm}$ & $25 / 15.4 \%$ \\
$20-40 \mathrm{~mm}$ & $59 / 35.8 \%$ & \\
$>40 \mathrm{~mm}$ & $81 / 49.1 \%$ & $50 / 30.6 \%$ \\
Target vessel & LAD \\
LCX & $17 / 10.2 \%$ & \\
RCA & $98 / 59.2 \%$ & $58 / 35.0 \%$ \\
Vessel diameter & $<3.0 \mathrm{~mm}$ \\
$3.0-4.0 \mathrm{~mm}$ & $107 / 65.0 \%$ & \\
Chronic total occlusion & \\
LAD & $11 / 22.4 \%$ & \\
LCX & $3 / 6.1 \%$ & \\
RCA & $35 / 71.4 \%$ & \\
\hline
\end{tabular}

$\mathrm{LAD}=$ left anterior descending, $\mathrm{LCX}=$ left circumflex, $\mathrm{RCA}=$ right coronary artery

\section{RESULTS}

Between March 2015 and August 2017, 165 patients with complicated coronary artery disease underwent PCI using the Guidezilla $^{\mathrm{TM}}$ extension catheter to enhance the delivery of a balloon or stent. Patient baseline clinical characteristics are summarized in Table 1 . The average patient age was $63.5 \pm$ 10.3 years, and the study included 132 males and 33 females. Thirty-two percent of patients had undergone previous coronary revascularization, and $6 \%$ had bypass grafting history. There were 9 patients $(5.4 \%)$ with a moderate-to-severe reduction in glomerular filtration rate (GFR) before interventional treatment. Almost half of patients ( $41.2 \%)$ suffered from diabetes. (Table 1)

Table 2 shows the characteristics of the target lesions. According to the American Heart Association/American College of Cardiology classification system, $86 \%$ of patients had complex Type C lesions and $13.9 \%$ had Type B lesions. Lesions ranged in length from $8 \mathrm{~mm}$ to $130 \mathrm{~mm}(\leq 20 \mathrm{~mm}$, $15.4 \%$; $20-40 \mathrm{~mm}, 35.8 \%$; > $40 \mathrm{~mm}, 49.1 \%)$. The right coronary artery $(59.2 \%)$ was the most common intervention vessel followed by the left ascending artery $(30.6 \%)$ and left circumflex artery $(10.2 \%)$. All treatment vessels were $>$ $2.5 \mathrm{~mm}$ in diameter $(<3.0 \mathrm{~mm}, 35.0 \% ; 3.0-4.0 \mathrm{~mm}, 65.0 \%)$. CTO accounted for $38 \%$ of all lesions, followed by tortuosity (28\%), heavy calcification (24\%), proximal stent thrombosis (9\%) and coronary artery origin anomalies (1\%) (Figure). All lesions were treated with the Guidezilla ${ }^{\mathrm{TM}}$ catheter combined with a 6-Fr mother-guide catheter [37.6\% EBU (Medtronic, USA), $26.1 \%$ JR (Cordis, USA), 24.2\% XBRCA (Cordis, 
USA), 6.7\% JL (Cordis, USA), 5.4\% AL (Boston Scientific, USA)]. Rotational atherectomy was used in 1 case.

In the postoperative target vessel in all patients, thrombolysis in myocardial infarction grade blood flow level was III, and residual stenosis was less than $20 \%$. A total of 142 patients underwent successful PCI using the Guidezilla ${ }^{\mathrm{TM}}$ extension catheter, resulting in a success rate of $86 \%$. Patients with failed PCIs were transferred to another hospital to undergo thoracotomy for cardiac surgery.

Death or acute myocardial infarction did not occur in any patient during or after surgery, and no catheter dissection or rupture occurred. No acute stent thrombosis, perforation caused by the guide wire, cardiac tamponade, or other events occurred. No vascular complications required urgent surgical treatment.

\section{DISCUSSION}

The results of this study show that the Guidezilla ${ }^{\mathrm{TM}}$ catheter is a useful tool for approaching challenging coronary lesions. In this study, there were 63 cases of CTO, 46 cases of tortuosity, 40 cases of severe calcification, 14 cases of proximal stent thrombosis, and 2 cases of coronary artery anomalies. Our results also highlight the feasibility and safety of the Guidezilla $^{\mathrm{TM}}$ catheter using a radial approach, achieving a high success rate $(86 \%)$ without complications when treating complex lesions.

Transradial catheterization has become the first choice for PCI in many hospitals in China and elsewhere because it has good compliance, fewer bleeding complications, and requires a shorter hospital stay [Cox 2004; Hildick-Smith 2010; Hou 2010]. Despite improvements in stent devices and PCI techniques, complex coronary anatomies, including calcification, extreme tortuosity, CTO, or proximal stent thrombosis remain a challenge in terms of procedural success because of poor vascular compliance and back-up support, especially during emergency PCI [Hynes 2011; Yamane 2012].

Recent studies have revealed the efficiency and safety the GuidelinerTM catheter for the percutaneous treatment of complex coronary lesions [Dursun 2016; Tunuguntla 2012]. The Guidezilla ${ }^{\mathrm{TM}}$ extension catheter is a mother-and-child catheter similar to the GuidelinerTM catheter. However, the Guidezilla ${ }^{\mathrm{TM}}$ extension catheter has a $25 \mathrm{~cm}$ distal catheter segment, which has a larger inner diameter $(1.42 \mathrm{~mm}$ versus $1.45 \mathrm{~mm})$ and smaller outer diameter $(1.70 \mathrm{~mm}$ versus $1.68 \mathrm{~mm})$.

Our results confirm those of previous reports on the Guidezilla $^{\mathrm{TM}}$ extension catheter in which the device was shown to be effective for percutaneous treatment of complex lesions. In the present study, 142 patients were successfully implanted with coronary stents using the Guidezilla ${ }^{\mathrm{TM}}$ extension catheter and balloon anchoring technique rather than conventional treatments. The Guidezilla ${ }^{\mathrm{TM}}$ extension catheter increases the support force in comparison with the traditional double thread, simple balloon anchoring and 5-in-6 catheter techniques by manipulating the guide catheter, providing coaxiality due to deep intubation into a coronary artery [Yew 2016].
Our data show that this technique mainly is applicable to CTO cases (49 cases), of which 58\% were from RCA. Chronic occlusive lesions often combine tortuosity, calcification and distal lesions, all of which increase the difficulty of guidewire insertion and subsequent balloon and stent traversal [Cuneo 2008]. Yew reported that the Guidezilla ${ }^{\mathrm{TM}}$ guide extension catheter can facilitate the delivery of long and bulky IN.PACT Falcon drug-coated balloons for the treatment of chronic total occlusion lesions [Yew 2015].

The Guidezilla ${ }^{\mathrm{TM}}$ extension catheter's ingenious structural design improves PCI success rates for complex lesions in several ways [Garcíablas 2015]: (1) It has a smaller outer diameter of $1.68 \mathrm{~mm}$, making it more convenient and effective in the use of the 6-Fr guidance catheter and has a larger internal diameter of $1.45 \mathrm{~mm}$ allowing more stable delivery of the interventional treatment device; (2) The Guidezilla ${ }^{\mathrm{TM}}$ extension catheter has excellent push. The push rod consists of stainless steel tubes, and the guide catheter is composed of wire braid and structural polymer, enhancing the push and bending resistance; (3) The outer surface of the Guidezilla ${ }^{\mathrm{TM}}$ extension catheter has a hydrophilic coating, which reduces friction and improves deliverability through tortuous lesions.

Although the Guidezilla ${ }^{\mathrm{TM}}$ extension catheter has many advantages, care must be taken to avoid any adverse events, such as stent stripping during the procedure [Ramanathan 2013; Waterbury 2016]. Extensive pushing of the Guidezil$1 \mathrm{a}^{\mathrm{TM}}$ extension catheter may cause further penetration of the guidewire, creating a potential risk of coronary artery perforation. While withdrawing the Guidezilla ${ }^{\mathrm{TM}}$ extension catheter, it is possible to unintentionally remove the guidewire from the coronary artery, and attention should be paid to the distal end of the guidewire to avoid such events [Roth 2016]. Waggoner et al reported a case of coronary stent dislodgement and stripping upon introduction of a balloon into the proximal Guidezilla ${ }^{\mathrm{TM}}$ edge [Waggoner 2015]. It is important to keep in mind that there is a risk of deep dissection in the coronary artery, and that surgery using the Guidezilla ${ }^{\mathrm{TM}}$ extension catheter should be done carefully and slowly under fluoroscopy.

\section{CONCLUSION}

In this single-center study with experienced operators, the Guidezilla $^{\mathrm{TM}}$ guide extension catheter was an effective and safe tool in the transradial treatment of complex coronary lesions. Use of the Guidezilla ${ }^{\mathrm{TM}}$ guide extension catheter can shorten the procedure time and ensure overall procedural success with a reduced complication rate in cases where adequate progress using angioplasty devices has not been achieved.

\section{LIMITATIONS}

First, the main limitation of this study is that it is a singlecenter, retrospective study. Second, it did not have a control group. Further study with multiple centers and more cases should be carried to examine this issue in greater detail. 
Larger, well-controlled randomized multicenter clinical studies are warranted.

\section{REFERENCES}

Chang YC, Fang HY, Chen TH, Wu CJ. 2013. Left main coronary artery bidirectional dissection caused by ejection of Guideliner catheter from the guiding catheter. Catheter Cardiovasc Interv 82:E215-20.

Cox N, Resnic FS, Popma JJ, Simon DI, Eisenhauer AC, Rogers C. 2004. Comparison of the risk of vascular complications associated with femoral and radial access coronary catheterization procedures in obese versus nonobese patients. Am J Cardiol 94:1174-7.

Cuneo A, Tebbe U. 2008. The management of chronic total coronary occlusions. Minerva Cardioangiol 56:527-41.

Di MC, Ramasami N. 2008. Techniques to enhance guide catheter support. Catheter Cardiovasc Interv 72:505-12.

Dursun H, Taştan A, Tanrıverdi Z, Özel E, Kaya D. 2016. GuideLiner catheter application in complex coronary lesions: experience of two centers. Anatol J Cardiol 16:333-9.

Garcíablas S, Núñez J, Mainar L, et al. 2015. Usefulness and Safety of a Guide Catheter Extension System for the Percutaneous Treatment of Complex Coronary Lesions by a Transradial Approach. Med Princ Pract 24:171-7.

Hildick-Smith DJ, Walsh JT, Lowe MD, Petch MC. 2010. Coronary angiography in the fully anticoagulated patient: The transradial route is successful and safe. Catheter Cardiovasc Interv 58:8-10.

Hou L, Wei YD, Li WM, Xu YW. 2010. Comparative study on transradial versus transfemoral approach for primary percutaneous coronary intervention in Chinese patients with acute myocardial infarction. Saudi Med J 31:158-62.

Hynes B, Dollard J, Murphy G, et al. 2011. Enhancing back-up support during difficult coronary stent delivery: single-center case series of experience with the Heartrail II catheter. J Invasive Cardiol 23:43-6.

Papayannis AC, Michael TT, Brilakis ES. 2012. Challenges associated with use of the GuideLiner catheter in percutaneous coronary interventions. J Invasive Cardiol 24:370-1.

Ramanathan PK, Redfern R. 2013. Use of guideliner catheter for anomalous right coronary artery angiography and intervention. J Invasive Cardiol 25:E20.

Roth C, Berger R, Scherzer S, et al. 2016. Comparison of magnetic wire navigation with the conventional wire technique for percutaneous coronary intervention of chronic total occlusions: a randomised, controlled study. Heart Vessels 31:1266-76.

Saeed B, Banerjee S, Brilakis ES. 2008. Percutaneous coronary intervention in tortuous coronary arteries: associated complications and strategies to improve success. J Interv Cardiol 21:504-11.

Tunuguntla A, Daneault B, Kirtane AJ. 2012. Novel use of the guideLiner catheter to minimize contrast use during PCI in a patient with chronic kidney disease. Catheter Cardiovasc Interv 80:453-5.

Waggoner T, Desai H, Sanghvi K. 2015. A unique complication of the GuideZilla guide extension support catheter and the risk of stent stripping in interventional \& endovascular interventions. Indian Heart J 67:381-4.

Waterbury TM, Sorajja P, Bell MR, et al. 2016. Experience and complications associated with use of guide extension catheters in percutaneous coronary intervention. Catheter Cardiovasc Interv 88:1057-65.

Yamane M. 2012. Current percutaneous recanalization of coronary chronic total occlusion. Rev Esp Cardiol (Engl Ed) 65:265-77.

Yew KL, Kang Z. 2015. Guidezilla guide extension catheter facilitated the delivery of long and bulky In. Pact Falcon drug-coated balloon for the treatment of chronic total occlusion lesion. Int J Cardiol 201:220-1.

Yew KL. 2016. Guidezilla guide extension catheter enhances the delivery of bioresorbable vascular scaffold in an anomalous coronary artery. Int J Cardiol 223:239-41. 